\title{
Investigating Self-Concept and Readiness of Self-Directed Learning Among Undergraduate Nursing Students in Jeddah
}

\author{
Hala A. Abdou ${ }^{1 *}$, Assistant Professor, B.Sc.N, M.Sc.N., Ph.D.N. Doaa Alshomrani, Ghadeer Alsomli, \\ Ahlamalsulami ${ }^{2}$ Professional nurse B.Sc.N. \\ 1* Nursing Administration Dept. Faculty of Nursing, Alexandria University, Egypt. Nursing Dept. College of \\ Nursing, King Saud Bin Abdul-Aziz University for Health Science, Jeddah KSA. \\ 2. Nursing Dept. College of Nursing, King Saud Bin Abdul-Aziz University for Health Science, Jeddah KSA
}

\begin{abstract}
In the last few decades development of nursing profession demands acquirement of skills that encourage lifelong learning. Self-concept is an important predictor and outcomes through educational learning environment of student personal interest and satisfaction. In addition, self-directed learning has become a focus for nursing education and critical skills for nursing students due to the complexity and changes in nursing profession development. Therefore, this study will integrated self concept and readiness of directed learning among nursing students' skills that gain and exposure during practice in the clinical settings to facilitate all over their professional career. This study aimed to investigate the relationship between self-concept and self-directed learning readiness among undergraduate nursing students in Jeddah. A descriptive correlational comparative study design was selected for fulfilling the aim of this study. The area of studying was carried out at College of Nursing - King Saud Bin Abdul-Aziz University for health science - Jeddah .The Study Subjects composed of junior and senior undergraduates nursing students at College of Nursing - King Saud Bin Abdul-Aziz University for health science - Jeddah. Non probability convenience sampling technique was utilized for this study. The estimated number of students' 50 junior and 50 senior nursing students from CONJ.A package composed of two questionnaires was used to collect data namely; Nurses Self - Concept Questionnaire. (NSCQ) and a SelfDirected Learning Readiness Scale (SDLRS). Data ware analyses using descriptive and implemented statistics. Main finding were that positively significant moderate correlation between self -concept and self-directed learning readiness dimensions among nursing students except for desire for learning. The majority of nursing students was high for self -concept and self-directed learning readiness dimensions. Finally, age, educational level and marital status are factors which have an effect on the nursing students' perception of self-concept dimensions, whereas marital status was influenced their SDLR dimensions. Therefore, the study recommended that educators should foster a partnership with students to help them assess their learning needs, develop specific learning objectives and promote life-long learning.
\end{abstract}

Keywords: self-concept, self-directing learning, readiness, nursing students

DOI: $10.7176 / \mathrm{JEP} / 10-2-07$

\section{Introduction}

Nursing education is well designed to help student's preparation in providing the holistic care to various patients populations by increasing students 'knowledge, and improving their skills in the clinical areas that help them in developing their values professionally. (1) Awareness of nursing students' knowledge about their abilities towards self-directed learning and self-learning concept are significant for nurse educators. In addition, for the learners a widespread independence chances they have because it is considered as the guarantee for the moving period from secondary schools to university education ${ }^{(1,2)}$ Köller et.al $(2001)$ they suggested that the less organized acquiring atmosphere is considered a significant transition for students' egocentricity. ${ }^{(3)}$

\subsection{Self - Concepts}

Self-concept leaning is defined as a psycho-social different specific domain for academic, physical, professional and an essential arbitrate flexible that impact the desirable outcomes. Self-concept is an essential outcome through nursing profession environments. It represents as the source for students' motivation concerns with how they believe and play as a moderator position for their responsibilities and performance. ${ }^{(4)}$ A positive selfconcept is desirable goal and high self-concept has the possible benefits of improving achievements and attaining self-fulfillment. In addition, it could be interpreted as the opportunity that linking between the internal thinking and feelings with the external events of a structure to guide the sense of 'self'. Generally, it seems that there is a positive relationship between the length of education and development of one's' professional self-concept that affects the degree in the academic systems. ${ }^{(5,6)}$ The professional self-concept is a significant concept for identifying how nursing students perceived their practiced competencies as related to patients care. It is defined as a group of knowledge and skills that nursing students have to apply their roles and performance in clinical settings. Moreover, positive professional self-concept supports the nursing students to perform a high level of their experiences under any pressure of the demanding atmosphere. ${ }^{(4,7)}$ 
During past years the self-learning concept has changed from abroad to a specified multi-dimensional and dynamic theory of self-perception of students' proficiency. A contemporary view of this study was developed by Cowin $(2001)^{(8)}$ based on the multidimensional self-concept model work of Shavelsonet al (1976). ${ }^{(9)}$ The Nursing Self-Concept Questionnaire (NSCQ) measures the improvement and achievement of self-concept in nursing education. It contains several dimensions and these dimensions are care, knowledge, staff relations, and leadership. Care described how nurses can think and feel about themselves as a profession regarding patients cares. In addition, knowledge refers to how nurses use their knowledge in nursing to solve patients' problems. Staff relations refer to how nurses see themselves as a part of exchange ideas with health professionals and working as a team member with other nursing colleagues. Lastly, leadership means to how nurses apply roles of leadership in nursing ${ }^{(5,8,10)}$ Therefore, professional self-concept is considered as the valuable concept in nursing education for helping the nursing students to understand their roles as becoming a professional nurse in their health care settings. ${ }^{(10)}$

\subsection{Self-directing learning}

Self-directed learning has growing a major interest at the university level through improving skills of critical thinking, autonomy, and problem solving among nursing students. Also, it identifies how nursing students direct their ability to gain knowledge for learning readiness as well as improve their confidence and innovative environments. In a regularly background the attributes of the nursing students' career will help them for facilitating their learning competencies. ${ }^{(11,12)}$ In the past few decades, due to the complexity and exchange in nursing education profession development such as nursing programs for undergraduates and post-graduates. Nursing students are encouraged to create a separated judgment by a set group of skills such as building their goals and create the learning plan to attain their goals. These skills are being on familiar terms with the readiness of self-directing learning. The readiness of self-directed learning is growing the self-assurance and the abilities for new situations among the nursing students. ${ }^{(13,14)}$

According to Fisher et.al (2010) the readiness of learning has been defined as to what extent the students have many characteristics such as their aptitude and individuality that are essential for self-directed learning ${ }^{(15)}$ The self-directed learners get control and accepts the freedom to learn and what is most be consider to be important for themselves. ${ }^{(16)}$ In other words, all students are able to learn but personality differences can affect their educational level including enthusiasm, worth, and honesty for learning. The self-directed learning process helps nursing students to inspire and evaluate their deficit in knowledge as well as to seek the methods to deal with these deficiencies. Also, they use accessible resources to support them in identifying the methods of choosing the appropriate problems solutions ${ }^{(17,18)}$.

Recently, a lot of studies in the educational field have mostly used Self-Directed Learning Readiness Scale (SDLRS) developed by Fisher et al. (2001). It is considered as one of the commonly scale for measuring three main subscales of SDLRS which are self-control, self-management, and desire for learning. The Self-Control subscale refers to the student's ability to evaluate their own learning objectives. ${ }^{(16)}$ The Self-Management subscale means that perceiving the self-correction for example, creativity, critical thinking, and formulating the regular study plan with using extra sources for solving the problems. Desire for Learning is considered as students' enthusiasm to learn and be open minded for initiate a new challenge vision. ${ }^{(19,20)}$

Many researchers were focused on the correlation between self-directed learning and academic achievement, personality traits. Also, they mentioned those self-directed learners more experience high degrees of effectiveness. ${ }^{(21,22)}$ Apparently, Saudi Arabia has several common changes in the health care delivery and the education system based on vision 2030. In teaching and learning establishment of educational climates the existing trends give emphasis to need of undergraduates nursing students at the university level toward gaining and developing a widespread variety of competencies, attributes which will allow them to be more autonomous and loyalties to one's profession because they must feel accountable for their clients, managers, and culture. Therefore, it is essential to investigate the factors affecting self-directedness such as approaches, capabilities and individuality characteristics needed for self-directed learning. ${ }^{(23,24)}$

\subsection{Significant of the study}

This study is significant to the participants and the management of the college because the results may enhance understanding of the relationship between readiness of self-directed learning and self-concept. It may allow the top authority of the college developing self-directed learning lifelong and adding to their mission and goal statements as well as increasing their self-possession, independence, enthusiasm and the competencies for permanent learning development. ${ }^{(15)}$ Also setting many strategies that play a role of strengthens qualities among nursing students. A successful integration of self-directed learning and self-concept into the courses syllabus has need of enough preparation of both learners as well as educators. Nursing student may benefit from this study because it may raise their awareness about how their self-concept my affect their readiness for self-directed learning and vice versa. ${ }^{(2,5,25)}$ Accordingly, the future research will be focus on advanced teaching strategies used 
by nurse educators to facilitate the application of new change in the curriculum and university atmosphere. In the same way, the nursing students will increase autonomy and controlling of their own self concept and readiness of learning throughout teaching and learning process. ${ }^{(24)}$

\section{The objective of the Study}

The purpose of this study is to investigate the relationship between self-concept and self-directed learning readiness among undergraduate nursing students in Jeddah.

\subsection{Specific Objectives:}

a. Assess the level of self-concept among junior and senior nursing students.

b. Assess the level of self-directed learning readiness among junior and senior nursing students.

c. Explore a statistically significant correlation between self-concept and self-directed learning readiness as related to socio-demographic characteristics.

d. Identify a statistically significant correlation between self-concept and self-directed learning readiness

\section{Materials and Methods}

\subsection{Study Design}

A descriptive correlational comparative study design was selected for fulfilling the aim of this study. This design helps to discover baseline information about self-concept and self-directing learning readiness and to evaluate the strength of the relationship between variables.

\subsection{Study Setting}

The area of study data was obtained from junior and senior undergraduate nursing students; at College of Nursing - King Saud Bin Abdul-Aziz for Health Science University - Jeddah

\subsection{Study Subjects}

A non-probability convenience sample technique was utilized for this study. All nursing students registered as regular junior and senior undergraduates nursing students at College of Nursing - King Saud Bin Abdulaziz University for health science - Jeddah. The target population for this study was included the estimated number of nursing students was around 100. They are classified into 50 Junior and 50 senior nursing students who agreed to take part in this study and accessible during the period of data gathering.

- Senior nursing students are defined in this study as the students' registered for courses considered at a senior Stream I Level 4, and Stream II Level 2 according to the unified curriculum and includes: Nursing Research, Critical Care Nursing, Community Health Nursing and Health Education,and Nursing Management and Leadership.

- As regards, the junior students are defined in this study as the students' registered for courses considered at a junior Stream I Level 4, and Stream II Level 2according to the unified curriculum and includes Fundamentals of Nursing I, II, Health Assessment, Microbiology, Clinical Nutrition, and Path-physiology.

\subsection{Study tools}

The questionnaire includes 3 parts:

3.4.1 Part 1: consisted of socio-demographic data of the nursing students' including the following variables: age, level of education, type of educational program, marital status and Academic Courses

3.4.2 Part 2, Nurses self - concept questionnaire (NSCQ)was created and developed by Cowin (2002), and was based on a multidimensional theory of self-concept by Shavelson et.al. ${ }^{(24,10)}$ It was used to measure nursing student' professional self-concept in 4 domains care (3 items),knowledge (4 items),staff relation (3 items), and leadership(4 items) with a total of (14 items).All 14 positively worded items were randomly assigned throughout the questionnaire. The questionnaire items were measured on an eight-point Likert scale ranging from 1 (definitely false)to 8 (definitely true). In addition, items scores for each item were summed and then divided by the number of items for each sub items. Overall scores can range from 14 to 112 , the cut of the point 112 divided by $2=56$. The score of participates that ranges from 14-56 will be considered as low self-concept, and the score that exceeds 56 was be considered as acceptable self-concept. The reliability of nurses self concept questionnaire (NSCQ) had been previously established (Cronbach's' alpha coefficient 0.960). ${ }^{(9,10)}$

3.4.3 Part 3, Self-Directed Learning Readiness Scale (SDLRS)is widely used in nursing education; it was developed and revised by Fisher and Fisher et.al (2001). It has been a valid and reliable questionnaire used to measure the readiness of the nursing students toward their self-directing learning overall lifetime considering their personality preferences, characteristics, skills, and behaviors. ${ }^{(15)}$ The SDLRS encompassed of 40 items distributed and categorized among the following three subscales; self-management (13 items), desire for learning (12 items), and self-control (15 items). Four items were negatively phrased and for analysis of data, the scored 
were reverse. The questionnaire items were weighted using on a 5-point Likert scale (1indicated strongly disagree and 5 indicated strongly agree) for participants response. The overall scores can range from 40 up to 200, in which above 150 scores indicates high degree of readiness for Self-directed learning while the score below or equal to 150 indicates a low level of self-directed learning readiness. The SDLRS has considered valid and reliable the Cronbach's' alpha coefficient was range from 0.87 to $0.96 .^{(20,21)}$

\subsection{Methods of data collection}

Three experts' panel from College of Nursing- Jeddah, King Saud Bin Abdul-Aziz University for Health Science to assess each item of the study questionnaires and provides their opinions for its content validity. A pilot study was carried out on $10(10 \%)$ of undergraduate nursing students affiliated to different educational levels, excluding from the study subjects, in order to ensure applicability, and clarity of questionnaires and estimating time spending for fulfilling the questionnaires. Accordingly, few statements were rephrased. The reliability level was computed using Cronbach's' alpha coefficient for the nurses self - concept questionnaire (NSCQ) (0.94) and self-directed learning readiness scale (SDLRS) (0.93). The expected time for completing the study questionnaires ranged from 15 to 25 minutes and covered a period of two weeks,

\subsection{Ethical consideration}

Written official approval from the college of nursing research committee CONJ - Jeddah was obtained for the permission to collect data. During the data collection period, all participants treated equally, voluntary, and anonymous with confidentiality. In the current study, the participants sign the consent form for their active involvement. A researcher developed a cover page for the current study, which involved the aim of the study and increases their cooperation throughout the study duration. The researcher has distributed the questionnaires to the participants, and they were available during data collection to answer any question raised by the participant and to collect the completed questionnaire. Students "identification was be coded and kept in locked files.

\subsection{Data management}

After gathering all completed questionnaires, data were coded, prepared and verified for analytical questionnaires. The data was statistically investigated using Statistical Package for the Social Science (SPSS) version 20.The evaluation of the study findings was handling statistically analyzed by using both descriptive and inferential tests. Mean, SD were employed to represent the descriptive statistics. In addition, for inferential analysis used Student t-test for comparison between the group of the current study and for comparing relationship among more than two groups, an ANOVA was appropriate for this study. Correlation between selfconcept and self-directed learning was tested by the use of the Pearson correlation coefficient. For an explanation of current study results, the test of significance was accepted at $\mathrm{p}<0.05$.

\section{Results}

Table 1: Socio-demographic characteristics of the undergraduate nursing students

\begin{tabular}{|c|c|c|}
\hline \multirow{2}{*}{ Socio-demographic characteristics } & \multicolumn{2}{|c|}{ Undergraduate nursing students $(n=100)$} \\
\hline & No & $\%$ \\
\hline \multicolumn{3}{|l|}{ Age } \\
\hline $19 y>22 y$ & 73 & 73.0 \\
\hline $26 y>23 y$ & 21 & 21.0 \\
\hline $30 y>27 y$ & 6 & 6.0 \\
\hline \multicolumn{3}{|l|}{ Educational level } \\
\hline First Level & 50 & 50.0 \\
\hline Fourth Level & 50 & 50.0 \\
\hline \multicolumn{3}{|l|}{ Educational programs } \\
\hline Stream I & 58 & 58.0 \\
\hline Stream II & 42 & 42.0 \\
\hline \multicolumn{3}{|l|}{ Marital Status } \\
\hline Single & 88 & 88.0 \\
\hline Married & 12 & 12.0 \\
\hline
\end{tabular}

Table 1: Present the distribution of socio-demographic characteristics of the undergraduate nursing students. Around three quarter of them (73\%) were aging between 19 years old to less than 22 years old. Also, half of the students $(50 \%)$ were in the first level and the rest half $(50 \%)$ were in the fourth level. $58 \%$ of the students were stream I and the reset $(42 \%)$ were stream II. The majority of the students $(88 \%)$ were single while $(12 \%)$ were married. 
Table 2: Undergraduates nursing students' level of nurses' self-concept dimensions

\begin{tabular}{|c|c|c|c|c|}
\hline \multirow[t]{2}{*}{ Dimensions of nurses' self-concept } & $\begin{array}{c}\text { Low self concept level } \\
\text { mean score } \geq 56\end{array}$ & $\begin{array}{c}\text { High self concept level } \\
\text { mean score } \leq 56\end{array}$ & \multirow[t]{2}{*}{ t- test } & \multirow[t]{2}{*}{$\mathbf{p}$} \\
\hline & $\mathbf{X} \pm \mathbf{S D}$ & $\mathbf{X} \pm \mathbf{S D}$ & & \\
\hline Care & $8.09 \pm 1.64$ & $20.09 \pm 3.81$ & 10.28 & $0.000 * *$ \\
\hline Knowledge & $10.00 \pm 2.19$ & $26.55 \pm 4.48$ & 12.05 & $0.000 * *$ \\
\hline Staff relation & $7.73 \pm 2.01$ & $20.36 \pm 3.32$ & 12.30 & $0.000 * *$ \\
\hline Leadership & $10.18 \pm 4.47$ & $26.71 \pm 5.08$ & 10.31 & $0.000 * *$ \\
\hline Overall scores & $36.00 \pm 7.31$ & $93.71 \pm 13.13$ & $-14.260-$ & $0.000 * *$ \\
\hline
\end{tabular}

$* \mathrm{p} \leq 0.05$ at $1 \%$ level denotes a significant difference .

$* * \mathrm{p} \leq 0.01$ at $1 \%$ level denotes a highly significant difference

Table 2: Portray undergraduates nursing students' level of nurses' self-concept dimensions.. This table indicates that there is a statistically significant association was observe for overall nurses' self -concept dimensions among undergraduate nursing students. The highest mean scores was identify for knowledge and leadership dimensions among undergraduates nursing students, while lowest means score was identify for care dimensions.

Table3: Nurses' self-concept dimensions of undergraduates nursing students as compared by educational level

\begin{tabular}{|c|c|c|c|c|c|c|c|c|c|c|c|}
\hline \multirow{3}{*}{$\begin{array}{l}\text { Dimension } \\
\text { s of nurses' } \\
\text { self- } \\
\text { concept }\end{array}$} & \multicolumn{9}{|c|}{ Educational level } & \multirow{3}{*}{$\begin{array}{c}F \\
\text { test }\end{array}$} & \multirow{3}{*}{$\mathbf{p}$} \\
\hline & \multicolumn{3}{|c|}{ Junior nursing students } & \multicolumn{3}{|c|}{ Senior nursing students } & \multicolumn{3}{|c|}{ Total nursing students } & & \\
\hline & Min & Max & $\mathrm{X} \pm \mathrm{SD}$ & Min & Max & $\mathrm{X} \pm \mathrm{SD}$ & Min & Max & $\mathrm{X} \pm \mathrm{SD}$ & & \\
\hline Care & 5.0 & 24.0 & $17.28 \pm 5.92$ & 8.0 & 24.0 & $20.26 \pm 3.99$ & 5.0 & 24.0 & $18.77 \pm 5.24$ & 8.73 & $0.004 * *$ \\
\hline Knowledge & 6.0 & 32.0 & $23.76 \pm 7.80$ & 10.0 & 32.0 & $25.70 \pm 5.38$ & 6.0 & 32.0 & $24.73 \pm 6.74$ & 2.10 & 0.15 \\
\hline $\begin{array}{l}\text { Staff } \\
\text { relation }\end{array}$ & 3.0 & 24.0 & $18.00 \pm 5.90$ & 9.0 & 24.0 & $19.94 \pm 3.98$ & 3.0 & 24.0 & $18.97 \pm 5.10$ & 3.72 & $0.06^{*}$ \\
\hline Leadership & 5.0 & 32.0 & $23.44 \pm 7.80$ & 6.0 & 32.0 & $26.34 \pm 6.30$ & 5.0 & 32.0 & $24.89 \pm 7.21$ & 4.18 & $0.04 *$ \\
\hline $\begin{array}{l}\text { Overall } \\
\text { scores }\end{array}$ & 19.0 & 111.0 & $82.48 \pm 25.85$ & 37.0 & 111.0 & $92.24 \pm 16.41$ & 19.0 & 111.0 & $87.36 \pm 22.09$ & 5.08 & $0.03 *$ \\
\hline
\end{tabular}

$* \mathrm{p} \leq 0.05$ at $1 \%$ level denotes a significant difference .

** $\mathrm{p} \leq 0.01$ at $1 \%$ level denotes a highly significant difference .

The dimension of nurses' self-concept dimensions of undergraduate nursing students as compared by educational level was shown in Table 3. The table illustrates the overall dimension of nurses' self-concept ranged from 19.00 to 111.0 with mean score $87.36 \pm 22.09$. The junior nursing students recorded the highest mean score in term of knowledge dimension23.76 \pm 7.80 as compared to leadership dimension26.34 \pm 6.30 for senior nursing students. While the lowest mean score was recorded for care dimension 17.28 \pm 5.92among junior nursing students as compared to staff relation dimension $19.94 \pm 3.98$ for senior nursing students. It was found that educational level had a statistically significant difference between junior and senior nursing students with selfconcept dimensions in term of care, staff relation, leadership, and overall self-concept scores $8.73 \mathrm{p} \leq 0.01,3.72$, $54.18,5.08 \leq 0.05$ respectively.

Table4: Undergraduates nursing students' level of readiness for self-directed learning dimensions

\begin{tabular}{|c|c|c|c|c|}
\hline \multirow[t]{2}{*}{$\begin{array}{l}\text { Dimensions of self- } \\
\text { directed } \\
\text { learning readiness }\end{array}$} & $\begin{array}{c}\text { High readiness for self } \\
\text { directing level mean score } \geq \\
120\end{array}$ & $\begin{array}{c}\text { Low readiness for self directing } \\
\text { level mean score } \geq 120\end{array}$ & \multirow[t]{2}{*}{ t- test } & \multirow[t]{2}{*}{$\mathbf{p}$} \\
\hline & $\mathbf{X} \pm \mathrm{SD}$ & $\mathrm{X} \pm \mathrm{SD}$ & & \\
\hline Self-Management & $29.11 \pm 3.92$ & $47.37 \pm 4.97$ & $\frac{-}{14.602-}$ & $0.00 * *$ \\
\hline $\begin{array}{ll}\text { Desire } & \text { for } \\
\text { Learning } & \\
\end{array}$ & $29.28 \pm 5.26$ & $49.33 \pm 4.49$ & $16.643-$ & $0.00 * *$ \\
\hline Self-Control & $35.06 \pm 4.21$ & $60.43 \pm 5.59$ & $\begin{array}{c}- \\
18.129-\end{array}$ & $0.00 * *$ \\
\hline Overall scores & $93.44 \pm 4.78$ & $157.12 \pm 10.69$ & $\begin{array}{c}- \\
24.665-\end{array}$ & $0.00 * *$ \\
\hline
\end{tabular}

$* \mathrm{p} \leq 0.05$ at $1 \%$ level denotes a significant difference .

$* * \mathrm{p} \leq 0.01$ at $1 \%$ level denotes a highly significant difference

Table 4: Show undergraduates nursing students' level of readiness for self-directed learning dimensions. The means scores of overall readiness for self-directed learning dimensions was significantly statistical relationship. In addition, higher mean scores was recorded for self-control dimension among undergraduates nursing students, however self-management was recorded as the lowest means scores for undergraduates nursing 
students.

Table5: Nursing students' level of readiness for self-directed learning dimensions as compared by educational level

\begin{tabular}{|c|c|c|c|c|c|c|c|c|c|c|c|}
\hline \multirow{3}{*}{$\begin{array}{l}\text { Dimension } \\
\text { s of self- } \\
\text { directed } \\
\text { learning } \\
\text { readiness }\end{array}$} & \multicolumn{9}{|c|}{ Educational level } & \multirow{3}{*}{$\begin{array}{c}F \\
\text { test }\end{array}$} & \multirow{3}{*}{$\mathbf{p}$} \\
\hline & \multicolumn{3}{|c|}{ Junior nursing students } & \multicolumn{3}{|c|}{ Senior nursing students } & \multicolumn{3}{|c|}{ Total nursing students } & & \\
\hline & $\begin{array}{c}\text { Mi } \\
\mathbf{n}\end{array}$ & $\begin{array}{c}\text { Ma } \\
\mathbf{x}\end{array}$ & $\mathbf{X} \pm \mathrm{SD}$ & $\begin{array}{c}\text { Mi } \\
\mathbf{n}\end{array}$ & $\begin{array}{c}\text { Ma } \\
\mathbf{x}\end{array}$ & $\mathbf{X} \pm \mathrm{SD}$ & $\begin{array}{c}\text { Mi } \\
\mathbf{n}\end{array}$ & $\begin{array}{c}\mathbf{M a} \\
\mathbf{x}\end{array}$ & $\mathbf{X} \pm \mathbf{S D}$ & & \\
\hline $\begin{array}{l}\text { Self- } \\
\text { Manageme } \\
\text { nt }\end{array}$ & $\begin{array}{c}20 . \\
0\end{array}$ & 57.0 & $\begin{array}{c}42.20 \pm 9.02 \\
4\end{array}$ & $\begin{array}{c}22 . \\
0\end{array}$ & 58.0 & $45.96 \pm 7.61$ & $\begin{array}{c}20 . \\
0\end{array}$ & 58.0 & $44.08 \pm 8.52$ & $\begin{array}{c}5.0 \\
7\end{array}$ & $\begin{array}{c}0.027 \\
*\end{array}$ \\
\hline $\begin{array}{l}\text { Desire for } \\
\text { Learning }\end{array}$ & $\begin{array}{c}25 . \\
0\end{array}$ & 59.0 & $\begin{array}{c}44.92 \pm 10.1 \\
7\end{array}$ & $\begin{array}{c}26 . \\
0\end{array}$ & 59.0 & $46.52 \pm 7.71$ & $\begin{array}{c}25 . \\
0\end{array}$ & 59.0 & $45.72 \pm 9.01$ & $\begin{array}{c}0.7 \\
9\end{array}$ & 0.377 \\
\hline $\begin{array}{l}\text { Self- } \\
\text { Control }\end{array}$ & $\begin{array}{c}22 . \\
0\end{array}$ & 71.0 & $\begin{array}{c}53.82 \pm 12.6 \\
1\end{array}$ & $\begin{array}{c}33 . \\
0\end{array}$ & 74.0 & $57.90 \pm 9.17$ & $\begin{array}{c}22 . \\
0\end{array}$ & 74.0 & $\begin{array}{c}55.86 \pm 11.1 \\
6\end{array}$ & $\begin{array}{c}3.4 \\
2\end{array}$ & 0.067 \\
\hline $\begin{array}{l}\text { Overall } \\
\text { scores }\end{array}$ & $\begin{array}{c}87 . \\
0\end{array}$ & $\begin{array}{c}177 . \\
0\end{array}$ & $\begin{array}{c}140.94 \pm 29 . \\
53\end{array}$ & $\begin{array}{c}88 . \\
0\end{array}$ & $\begin{array}{c}186 . \\
0\end{array}$ & $\begin{array}{c}150.38 \pm 22 . \\
38\end{array}$ & $\begin{array}{c}87 . \\
0\end{array}$ & $\begin{array}{c}186 . \\
0\end{array}$ & $\begin{array}{c}145.66 \pm 26 \\
49\end{array}$ & $\begin{array}{c}3.2 \\
5\end{array}$ & 0.075 \\
\hline
\end{tabular}

$* \mathrm{p} \leq 0.05$ at $1 \%$ level denotes a significant difference .

$* * \mathrm{p} \leq 0.01$ at $1 \%$ level denotes a highly significant difference .

Table 5 shows nursing students' level of readiness for self-directed learning dimensions as compared by educational level. The table illustrates that the overall dimension of self-directed learning readiness ranged from 87.0 to 186.0 with mean score $145.66 \pm 26.49$. This table reflects that it is statistically significant was found between dimensions of self-directed learning and educational level in term of self-management dimension $5.07 \mathrm{p}$ $\leq 0.05$. Also, the highest mean scores were described for self-control dimension among junior and senior nursing students $53.82 \pm 12.61$ and 57.90 \pm 9.17 respectively. On the other hand, the lowest means score was selfmanagement dimension for both junior and senior nursing students $42.20 \pm 9.024$ and 45.96 \pm 7.61 respectively.

Table 6: Relationship between socio-demographic characteristics of nursing students and their nurses' self-concept

\begin{tabular}{|c|c|c|c|c|c|}
\hline \multirow{3}{*}{$\begin{array}{l}\text { Socio-demographic } \\
\text { characteristics }\end{array}$} & \multicolumn{5}{|c|}{ Dimensions of nurses' self-concept } \\
\hline & Care & Knowledge & Staff relation & Leadership & $\begin{array}{c}\text { Overall } \\
\text { scores }\end{array}$ \\
\hline & $\mathbf{X} \pm$ SD & $\mathbf{X} \pm$ SD & $\mathbf{X} \pm$ SD & $\mathbf{X} \pm$ SD & $\mathbf{X} \pm$ SD \\
\hline \multicolumn{6}{|l|}{ Age group } \\
\hline $19 y>22 y$ & $19.27 \pm 5.15$ & $25.45 \pm 6.90$ & $19.49 \pm 5.14$ & $25.37 \pm 7.17$ & $89.59 \pm 22.43$ \\
\hline $23 y>26 y$ & $18.71 \pm 4.75$ & $23.86 \pm 5.37$ & $18.67 \pm 4.10$ & $24.71 \pm 6.94$ & $85.95 \pm 18.099$ \\
\hline $27 y>30+y$ & $12.83 \pm 5.08$ & $19.00 \pm 6.90$ & $13.67 \pm 5.47$ & $19.67 \pm 7.66$ & $65.17 \pm 20.86$ \\
\hline F - test & 4.49 & 2.87 & 3.88 & 1.77 & 3.62 \\
\hline P-Value & $0.01 *$ & $0.06 *$ & $0.02 *$ & 0.175 & $0.03 *$ \\
\hline \multicolumn{6}{|l|}{ Educational Programs } \\
\hline Stream I & $18.95 \pm 5.61$ & $25.35 \pm 7.42$ & $19.02 \pm 5.67$ & $25.64 \pm 7.55$ & $88.95 \pm 24.73$ \\
\hline Stream II & $18.52 \pm 4.74$ & $23.88 \pm 5.64$ & $18.91 \pm 4.27$ & $23.86 \pm 6.65$ & $85.17 \pm 17.88$ \\
\hline$t$ - test & 0.40 & 1.07 & 0.11 & 1.22 & 0.84 \\
\hline$P$-Value & 0.69 & 0.29 & 0.91 & 0.22 & 0.40 \\
\hline \multicolumn{6}{|l|}{ Marital Status } \\
\hline Single & $19.65 \pm 4.66$ & $25.48 \pm 6.22$ & $19.729 \pm 4.68$ & $25.86 \pm 6.76$ & $90.71 \pm 19.97$ \\
\hline Married & $12.33 \pm 4.87$ & $19.25 \pm 8.06$ & $13.50 \pm 4.85$ & $17.75 \pm 6.50$ & $62.83 \pm 22.19$ \\
\hline$t-$ test & 5.074 & 3.135 & 4.296 & 3.915 & 4.477 \\
\hline $\mathbf{P}-$ Value & $0.00 * *$ & $0.02 *$ & $0.00 * *$ & $0.00 * *$ & $0.00 * *$ \\
\hline
\end{tabular}

$* \mathrm{p} \leq 0.05$ at $1 \%$ level denotes a significant difference .

$* * \mathrm{p} \leq 0.01$ at $1 \%$ level denotes a highly significant difference .

Table 6: describe the relationship between socio-demographic characteristics of nursing students and their nurses' self-concept. This table highlighted that a statistically significant relation was documented between selfconcept dimensions among nursing students related to age groups and marital status $(\mathrm{F}=3.62 \mathrm{p}<0.05$ and $\mathrm{t}$-test $=4.477 \mathrm{p}<0.01$ respectively). The highest mean score was observed for those aging between 19 years old and less than 22 years old 25.45 \pm 6.90 as compared to those aging between 27 years old to less than 30-years-old $19.67 \pm 7.66$. Also, the highest mean score was observed for single nursing students $(25.86 \pm 6.76$ than married nursing students $19.25 \pm 8.06$. 
Table 7: Relationship between socio-demographic characteristics of nursing students and their readiness for self-directed learning

\begin{tabular}{|c|c|c|c|c|}
\hline \multirow{3}{*}{$\begin{array}{c}\text { Socio-demographic } \\
\text { characteristics }\end{array}$} & \multicolumn{4}{|c|}{ Dimensions of nurses' self-directed learning readiness } \\
\hline & $\begin{array}{c}\text { Self- } \\
\text { management }\end{array}$ & $\begin{array}{l}\text { Desire for } \\
\text { learning }\end{array}$ & Self-control & $\begin{array}{c}\text { Overall } \\
\text { scores }\end{array}$ \\
\hline & $\mathbf{X} \pm$ SD & $\mathbf{X} \pm \mathbf{S D}$ & $\mathbf{X} \pm$ SD & $\mathbf{X} \pm \mathrm{SD}$ \\
\hline \multicolumn{5}{|l|}{ Age group } \\
\hline $19 y>22 y$ & $44.70 \pm 8.32$ & $46.19 \pm 8.43$ & $56.86 \pm 10.49$ & $147.75 \pm 24.90$ \\
\hline $23 y>26 y$ & $42.57 \pm 9.68$ & $44.38 \pm 11.36$ & $54.19 \pm 13.43$ & $141.14 \pm 32.64$ \\
\hline $27 y>30+y$ & $41.83 \pm 6.52$ & $44.67 \pm 7.474$ & $49.50 \pm 9.31$ & $136.00 \pm 21.12$ \\
\hline $\mathbf{F}$ - test & 0.727 & 0.368 & 1.519 & 0.931 \\
\hline $\mathbf{P}-$ Value & 0.486 & 0.693 & 0.224 & 0.398 \\
\hline \multicolumn{5}{|l|}{ Educational Programs } \\
\hline Stream I & $44.29 \pm 8.63$ & $45.95 \pm 8.87$ & $56.21 \pm 10.89$ & $146.45 \pm 26.12$ \\
\hline Stream II & $43.79 \pm 8.45$ & $45.41 \pm 9.30$ & $55.38 \pm 11.64$ & $144.57 \pm 27.29$ \\
\hline$t$ - test & 0.293 & 0.296 & 0.364 & 0.348 \\
\hline $\mathbf{P}$-Value & 0.770 & 0.768 & 0.717 & 0.729 \\
\hline \multicolumn{5}{|l|}{ Marital Status } \\
\hline Single & $44.64 \pm 8.34$ & $46.03 \pm 8.62$ & $56.92 \pm 10.74$ & $147.59 \pm 25.43$ \\
\hline Married & $40.00 \pm 9.07$ & $43.42 \pm 11.64$ & $48.08 \pm 11.58$ & $131.50 \pm 30.92$ \\
\hline $\mathrm{t}$ - test & 1.789 & 0.944 & 2.650 & 2.003 \\
\hline $\mathbf{P}$-Value & 0.077 & 0.348 & $0.009^{*}$ & $0.048^{*}$ \\
\hline
\end{tabular}

$* \mathrm{p} \leq 0.05$ at $1 \%$ level denotes a significant difference .

$* * \mathrm{p} \leq 0.01$ at $1 \%$ level denotes a highly significant difference .

The relationship between socio-demographic characteristics of nursing students and their readiness for selfdirected learning was shown in Table 7. This table present that nursing students had highest mean score of selfdirected learning readiness who were single with age group between 19 years old and less than 22 years old, had stream I. (147.59 $\pm 25.43,147.75 \pm 24.90$, and146.45 \pm 26.12 respectively). On the other hands, they perceived the lowest mean scores were represent the perception of self-directed learning readiness dimensions pertain to married, age group from 27 years old to less than 30 years old and holding a stream II $(131.50 \pm 30.92,136.00 \pm 21.12$, and $144.57 \pm 27.29$ respectively). Moreover, there was no statistically significant difference among nursing students mean scores for all dimensions of self-directed learning readiness and their socio-demographic characteristics except for marital status

Table 8: Correlation coefficient between mean scores of nurses' self-concept and self-directed learning readiness dimensions pertaining to nursing students

\begin{tabular}{|c|c|c|c|c|c|c|}
\hline \multirow{2}{*}{\multicolumn{2}{|c|}{$\begin{array}{l}\text { Dimensions of self-directed } \\
\text { learning readiness }\end{array}$}} & \multicolumn{5}{|c|}{ Dimensions of nurses self-concept } \\
\hline & & \multirow{2}{*}{$\begin{array}{l}\text { Care } \\
0.185\end{array}$} & \multirow{2}{*}{$\begin{array}{c}\text { Knowledge } \\
0.200^{*}\end{array}$} & \multirow{2}{*}{$\begin{array}{c}\text { Staff relation } \\
0.139\end{array}$} & \multirow{2}{*}{$\begin{array}{c}\text { Leadership } \\
0.226^{*}\end{array}$} & \multirow{2}{*}{$\begin{array}{c}\begin{array}{c}\text { Total nurses } \\
\text { self-concept }\end{array} \\
0.210^{*}\end{array}$} \\
\hline & $\mathrm{r}$ & & & & & \\
\hline Self-management & $\mathrm{P}$ & 0.066 & 0.046 & 0.167 & 0.024 & 0.036 \\
\hline \multirow{2}{*}{ Desire for learning } & $\mathrm{r}$ & 0.173 & 0.169 & 0.162 & 0.129 & 0.172 \\
\hline & $\mathrm{P}$ & 0.085 & 0.092 & 0.108 & 0.200 & 0.087 \\
\hline \multirow{2}{*}{ Self-control } & $\mathrm{r}$ & $0.280^{* *}$ & $0.236^{*}$ & $0.261^{* *}$ & $0.266^{* *}$ & $0.286^{* *}$ \\
\hline & $\mathrm{P}$ & 0.005 & 0.018 & 0.009 & 0.007 & 0.004 \\
\hline \multirow{2}{*}{$\begin{array}{c}\text { Total self-directed learning } \\
\text { readiness }\end{array}$} & $\mathrm{r}$ & $0.236^{*}$ & $0.221^{*}$ & $0.210^{*}$ & $0.229^{*}$ & $0.247^{*}$ \\
\hline & $\mathrm{P}$ & 0.018 & 0.027 & 0.036 & 0.022 & 0.013 \\
\hline
\end{tabular}

$* \mathrm{p} \leq 0.05$ at $1 \%$ level denotes a significant difference .

$* * \mathrm{p} \leq 0.01$ at $1 \%$ level denotes a highly significant difference .

Table 8: represent the correlation coefficient between mean scores of nurses' self-concept and self-directed learning readiness dimensions pertaining to the nursing students. The results revealed that self-directed learning readiness and self-concepts dimensions were positively moderate correlation except for the desire for learning dimension. 
Figure 1 represent that the majority of undergraduates nursing students (89\%) confirmed as a high level of nurses' self-concept $(\leq 56)$

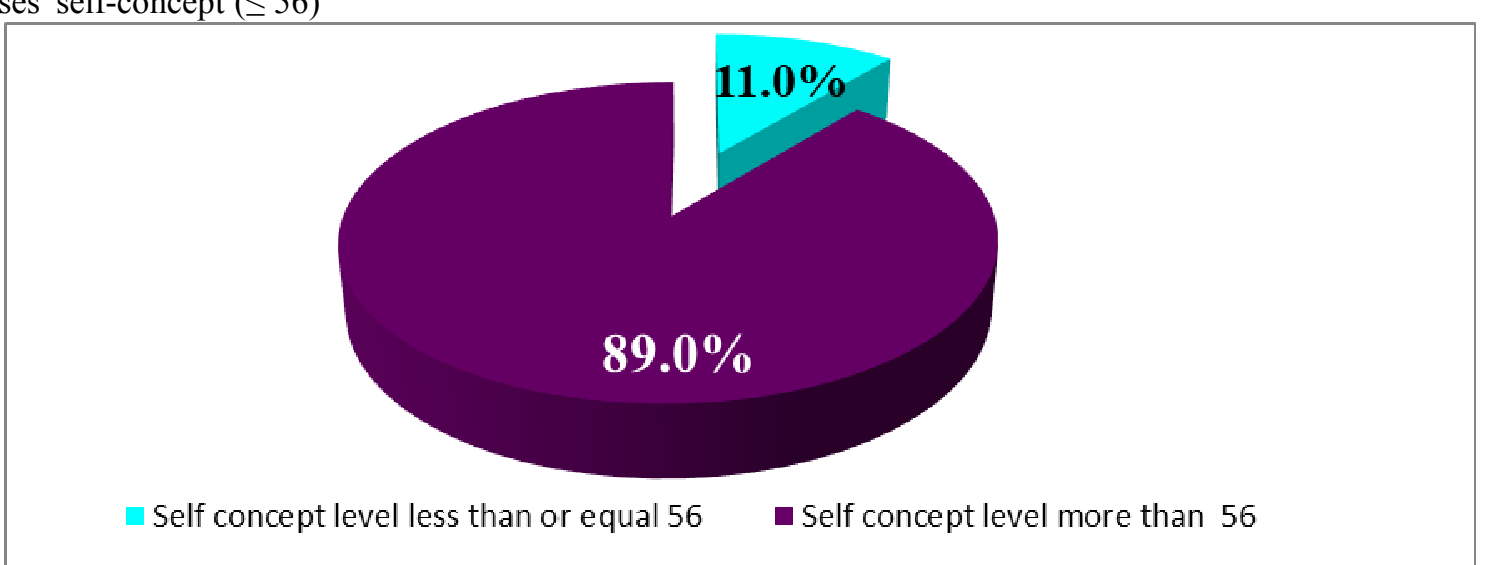

Figure 1: Nursing students' Level of nurses' self-concept

Figure 2 denote that the majority of undergraduates nursing students (82\%) approve as a high level of Readiness for Self-Directed Learning $(\leq 150)$

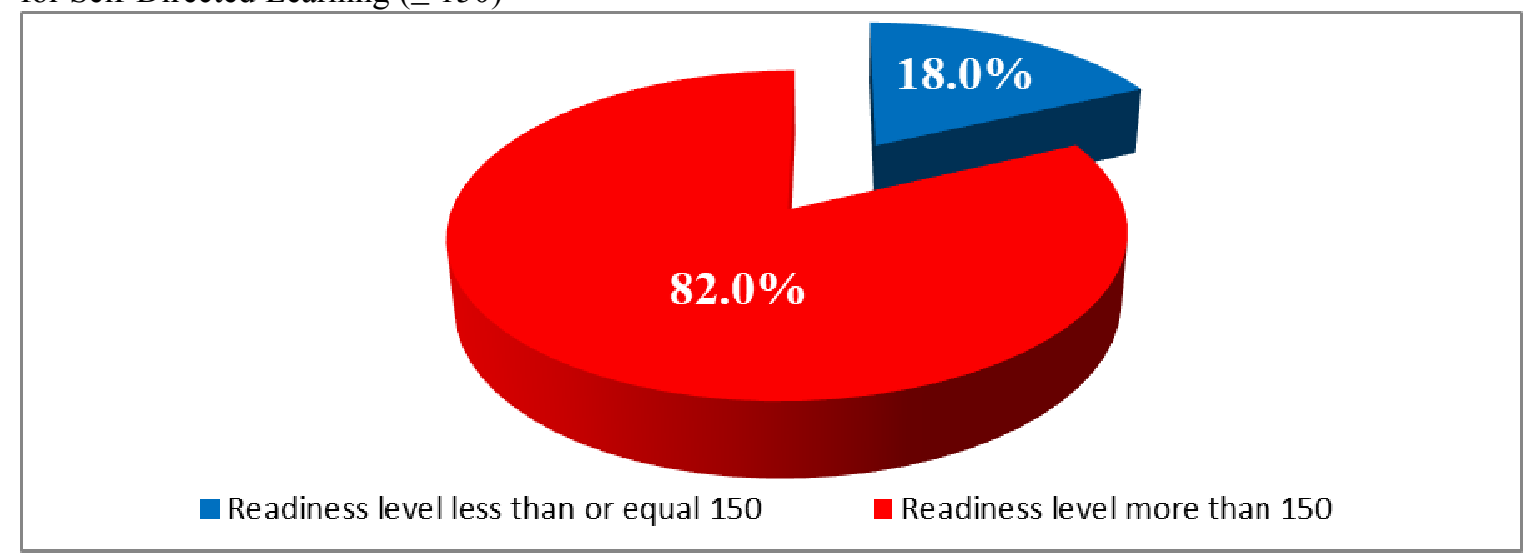

Figure 2: Nursing students' Level of Readiness for Self-Directed Learning

\section{Discussion}

In the 21st Century frameworks for self concept and self directed learning were well known as significant skills among nursing students. In addition, nursing a professional development different skill that encourage permanent and continuous learning using a well planned formal education curriculum through new change in nursing knowledge and practice context. ${ }^{(26)}$

Generally, drawn from the present study finding that there was a significant positively moderate correlation between mean scores of self directed learning readiness and self concepts dimensions were except for desire for learning dimension. This finding goes incongruence with Pitt et.al (2012), who concluded that strong correlation between processional self concept and self directing learning among nursing students in which affect their clinical performance to carry out efficiently and effectively in the organizational health care. ${ }^{(27)}$ Specifically, the current finding can be justified that professional self-concept is considered as an academic motive issue that help learners experience to increase their feeling of accountability, professional improvement and development. Moreover self-directed learning readiness enhance stimulation for self-government one's learning and independency skills for making an appropriate decision and fostering problem solving in the clinical settings. ${ }^{(15)}$

The present study provides complete available information about self concept levels among nursing students. The findings revealed that the majority of nursing students $89 \%$ with overall mean score $87.36 \pm 22.09$ regardless their educational level perceived highest level of self concept dimensions. This finding is in line with Cowin and Hengstberger (2006), they stated that high level of profession self concept among nursing students mostly retain as a in the first year of their job after their graduation. ${ }^{(28)}$ This finding could be attributed to increase in the professional self concept levels encourage nursing students to perform the patient care in positively manner and encourage their job satisfaction and retention. Also, it is help them in move into a nursing profession. ${ }^{(10)}$ On the other hand, the results of this study contradicts the foundations of Jahanbin Iet.al (2012), they found that the students' professional self-concept have lessenlevel when compared to other research. ${ }^{(29)}$ Moreover, it was identified that care, staff relation, leadership of self-concept dimensions document a 
significant difference relationship among junior and senior nursing students. This finding was remarkably identified from Marsh et.al (2011); they indicated that high significant correlation was found between 'knowledge', 'care', and 'staff relations' dimensions of self concept dimensions. ${ }^{(30)}$ In the same line with the previous results, it was identified that the junior nursing students perceived the highest mean score of selfconcept in term of knowledge dimension as compared to leadership dimension for senior nursing students. This result could be contributed to junior nursing students had no experience of patient care because they don't attend any clinical situation in the hospital. They educated how incorporated and applied nursing knowledge and nursing process into patients care in health care setting. Moreover, senior nursing students feel more selfconfidence, working as team and responsible for planning of patient care which used to improve their experience and leadership skills. ${ }^{(10,15)}$ The finding agrees with results of those of Arthur and Randle (2007), they explained that exchange of complex knowledge by nursing students will help them in providing high quality of patient care because they increase feeling of self-confident and reflects in their constructive judgment. ${ }^{(31)}$

In this descriptive study, the current findings show that nursing students in CONJ - King Saudi Bin Abdulaziz for health and Science University the majority of them were perceived positive attitude toward selfdirected learning readiness dimensions $(82 \%)$ with overall mean score $145.66 \pm 26.49$ regardless their educational level. This finding is in agreement with results of Iran, Saudi Arabia, and Indian. They concluded that overall

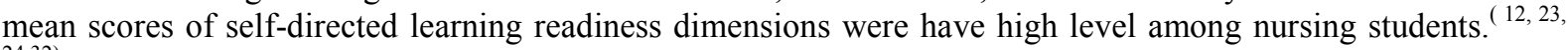
${ }^{24,32)}$ However, the study finding is opposite to Yuan (2012) study, they founded that only two third of B.Sc.N students at Chinese have higher- level of self-directed learning readiness dimensions. ${ }^{(2)}$ This finding could be contributed to innovative vision 2030, change in the higher education will be focuses on independent learning for students using strategy of central learning to facilitate effective education process and encourage their needs to become self-governing and autonomous learners.

Generally, senior nursing students had higher mean scores of overall self-directed learning readiness dimensions than junior nursing students .The same results were reported by Klunklin, et.al (2010) who stated that higher level of self directing readiness dimensions among senior students as compared to junior which it can be affect strengthen and improvement of self directing readiness process and characteristics. ${ }^{(20)}$

One possible explanation may be due to different factors affecting readiness of self directing among senior nursing students which affect their attitudes and behaviors toward enthusiasm to learn in their clinical practice settings. Also they work independently for formulate their learning objectives and evaluating learning outcomes.

In accordance with the finding of the previous results, among the three subscales of SDL, it was found that self-control was a highly mean scores reported subscale for SDLR among junior and senior nursing students while self-management subscale were lowest mean scores respectively. This result was expected and could be attributed to the fact that, self-control subscale emphasis on self-confidence, self-responsibility and work independently in clinical practice and situations, which encourage senior and junior nursing students to apply adult learning theory and get ready for the creation a new strategy for their professional nursing careers. However, self-management subscale needs additional efforts and resources for education in nursing students with regulating atmospheres for knowledge and skills in teaching and learning less problematic. Also the same finding is similar to the results of research by Alkorashy and AbuAssi (2016) as well as El Seesy N. et.al (2017). ${ }^{(24,33)}$ However this finding is inconsistent with Williams et.al. (2013), which noticed that the highest mean sore was documented for desire for learning dimension while moderate score for each self-control and selfmanagement dimension. ${ }^{(35)}$

Based on the present study results, it is interesting to notice that overall self-concept and readiness of selfdirecting dimensions were varied significantly among nursing students' socio-demographic characteristics in term of age and marital status. Concerning age groups, the present study show a statistically significant association between nursing students aged from $19 \mathrm{y}-22 \mathrm{y}$ had highest mean scores as compared to other age group with self concept and its related subscales, excluding the leadership subscale. This finding proves that positive significant association between self concept dimensions and nursing students' age that may be develop and gain knowledge by experience. This result matched with Williams et.al. (2013) who highlight that younger students have higher mean scores of self concepts subscales in comparing to older students.. ${ }^{(35)}$ This could be explained in the light of younger students encounter with different problems and struggles during their clinical practice and they need developing their knowledge and skill to be more autonomous and confident in selecting their decisions. Regarding marital status it was notice that nursing students perceived of overall means scores of self concept and readiness of self directing subscales except for self management and desire for learning was associated positively with single nursing students as compared to married nursing students. This result may be due to married students improper oversee their time for study well because their family responsibilities. Also, education in nursing environment depends on the different elements in Saudi culture. This finding contrasts the results of and Yuan, H. (2012) and El-Gilany and Abusaad (2012) they indicated that no statistical association between marital status and overall self-concept and readiness of self-directing subscales. ${ }^{(2,23)}$ 


\section{Conclusions and recommendation}

The findings of the current study concluded that nursing students were generally had obviously positively significant moderate correlation between self -concept and self-directed learning readiness dimensions except for the desire for learning. Self -concept levels of the majority of nursing students was high in term of knowledge and leadership dimensions. The junior nursing students perceived higher mean score in term of knowledge dimension as compared to leadership dimension among senior nursing students. The SDLR levels among nursing students were high. The nursing students' self-control dimension was highest as compared to selfmanagement and desire for learning of SDLR dimensions. Finally, age, educational level, and marital status are factors which have an effect on the nursing students' perception of self-concept dimensions, whereas marital status only was influenced their SDLR ability and dimensions. Therefore, the study recommended that the need to monitor self-concept and self-directed learning development strategies and integration within teaching and learning context of the curriculum through the mutual collaboration of knowledge, skills for both students and faculty. Promote self-directed learning as a central strategy for developing competency of the nursing students in the clinical practice which emphasis on critical thinking and problem-solving. Active participation of nursing students in determine their learning needs and take responsibility of learning for their professional and selfdevelopment

\section{References}

[1] Li, X.L., Deng, S.Y., Chen, Y.L., (2009). Establishment of a new model for nursing talents training and a brand-new learning. Chinese Nursing Research 23 (3B), 737-738.

[2] Yuan, H. (2012). Chinese baccalaureate nursing student readiness for self-directed learning. Nurse Education Today, (32), 427-431.

[3] Köller, O., Baumert, J., \& Schnabel, K. (2001). Does interest matter? The relationship between academic interest and achievement in mathematics. Journal for Research in Mathematics Education, 32, 448-470.

[4] Angel, E., Craven, R., Denson, N. (2012). The Nurses Self-Concept Instrument (NSCI): Assessment of psychometric properties for Australian domestic and international student nurses. International Journal of Nursing Studies, 49, $880-886$.

[5] Kelly; S., Courts; N (2007). The professional self-concept of new graduate nurses. Nurse Education in Practice 7, 332-337.

[6] Marsh, H.W; Craven, R.G (2006). Reciprocal effects of self-concept and performance from a multidimensional perspective: beyond seductive pleasure and uni-dimensional perspectives. Perspectives on Psychological Science 1 (2), 133-163.

[7] Takase M.; Kershaw E.; Burt L (2002). Does public image of nurses matter?. Journal of Professional Nursing 18 (4):196-205.

[8] Cowin, L (2001). Measuring nurses' self-concept. West. J. Nurs. Res. 23, 313-325.

[9] Shavelson, R. J., Huber, J.J.; and Stanton, G. C. (1976). Self-concept: Validation of construct interpretations. Review of Educational Research in Higher Education, 46, 407-441.

[10] Cowin, L.; Craven R.; Johnson M.; and Marsh H (2006). A longitudinal study of student and experienced nurses' self-concept. Collegian 13, 3 .

[11] Levett-Jones LT (2005). Self-directed learning: implications and limitations for undergraduate nursing education. Nurse Educ.Today 25: 363-368.

[12] Safavi, M.; Schooshtari S.H.; Mahmoodi, M., and Yarmohammadian, M (2010). Self-directed learning readiness and learning styles among nursing students of Isfahan University of Medical Sciences. Iranian Journal of Medical Education 10 (1), 27-35.

[13] Shen, W.; Chen, H.; and Hu, Y. (2014).The validity and reliability of the self-directed learning instrument (SDLI) in mainland Chinese nursing students. BMC Medical Education, 1-7.

[14] Payne, S.; Rundquist, P.; Harper, W.; and Gahimer, J. (2013).self-directed learning readiness and selfdetermination for selected rehabilitation professional students: the impact of clinical education. International Journal of Self-Directed Learning, 10(1), 35-45.

[15] Fisher M.J., King, J (2010). The self-directed learning readiness scale for nursing education revisited: a confirmatory factor analysis. Nurse Education Today 30 (1), 44-48.

[16] Fisher MJ.; King, J.; and Tague, G (2001). Development of a self-directed learning readiness scale for nursing education. Nurse Education Today 21, 516-525.

[17] O'Shea, E (2003). Self-directed learning in nurse education: a review of the literature. Journal of Advanced Nursing 43 (1), 62-70.

[18] Karimi, R., Arendt, C.S., Cawley, P., Buhler, A.V., Elbarbry, F., Roberts, S.C., (2010). Learning bridge: curricular integration of didactic and experiential education. American Journal of Pharmaceutical Education 74 (3) Article 48.

[19] Cazan A.; Schiopca, B (2014). Self-directed learning, Personality traits and academic achievement. Social 
and Behavioral Sciences 127, 640-644.

[20] Klunklin, A.; Viseskul N.; Sripusanapan, A. (2010). Readiness for self-directed learning among nursing students in Thailand. Nursing and Health Sciences 12, $177-181$.

[21] Williamson, N. (2007). Development of a self-rating scale for self-directed learning. Nurse Researcher, $14(2), 66-83$.

[22] Lounsbury J.; Levy J.; Park S.; Gibson L.; and Smith, R. (2009). An investigation of the construct validity of the personality trait of self-directed learning. Learning and Individual Differences, 19, 411-418.

[23] El-Gilany, A and El Sayed Abusaas, F. (2012). Self-directed learning readiness and learning styles among Saudi undergraduate nursing students. Nursing Education today 33, 1040-1044.

[24] Alkorashy H.E and AbuAssi N. E. (2016). Readiness for Self-Directed Learning among Bachelor Nursing Students in Saudi Arabia: A Survey-Based Study. International Journal of Nursing Education and Research 4(2): April- June.

[25] Oliveira, A. L., \& Simões, A. (2006). Impact of socio-demographic and psychological variables on the selfdirectedness of higher education students. International Journal of Self- Directed Learning, 3(1), 1-60.

[26] AfshaBadshahSaidNasreen Ghani Awal khan MusarratKiramat Examination of Self-Directed Learning Readiness among Baccalaureate Nursing Students in Peshawar Pakistan..International Journal of Innovative Research and Development Vol 4 Issue 2 257- 2622015

[27] Pitt V, Powis D, Levett-Jones T, Hunter S (2012). Factors influencing nursing students' academic and clinical performance and attrition: An integrative literature review. Nurse Education Today.;32(8):903-13

[28] Cowin, L.S., Hengstberger-Sims, C., (2006). .New graduate nurse self-concept and retention: a longitudinal survey. Int. J. Nurs. Stud. 43, 59-70.

[29] Jahanbin I, Badiyepeyma Z, Sharif F, Ghodsbin F, Keshavarzi S (2012). The impact of teaching professional self-concept on clinical performance perception in nursing students.Life Science Journal.;4:9.

[30] Marsh, H.W., Nagengast, B., Morin, A.J.S., Parada, R.H., Craven, R.G., Hamilton, L.R., 2011. Construct validity of the multidimensional structure of bullying and victimization: an application of exploratory structural equation modeling. Journal of Educational Psychology 103, 701-732.

[31] Arthur, D., Randle, J., 2007. The professional self-concept of nurses: a review of the literature from 19922006. The Australian Journal of Advanced Nursing 24 (3),60-63.

[32] Kar, S.S., Premarajan, K.C., Ramalingam. A., Iswarya, S., Sujiv, A., Subitha L. (2014) Self-directed learning readiness among fifth semester MBBS students in a teaching institution of South India, Education for Health, 27, 3, pp. 289-292.

[33] El Seesy N.A.,SofarbS.M., Al-Battawic J.A (2017). Self-directed learning readiness among Nursing Students atKingAbdulazizUniversity, Saudi Arabia. IOSR Journal of Nursing and Health Science (IOSRJNHS),V6( 6) Ver. III. (Nov.- Dec .2017), PP 14-24

[35] Williams B, Boyle M, Winship C, Brightwell R, Devenish S, Munro G (2013). Examination of self-directed learning readiness of paramedic undergraduates: A multi-institutional. Study Journal of Nursing Education and Practice; 3 (2): 103-11.

\section{ACKNOWLEDGEMENTS}

Researcher appreciates and thanks all nursing students for their valuable participation in carrying out the study questionnaires

\section{Conflicts Of Interest Disclosure:}

The authors declare that there is no conflict of interest.

10. First A. Author (Hala A. Abdou) was born in Egypt in 1971. She received the Bsc. Nursing, M.E., and Ph.D. degrees from Alexandria University, in 1993, 2001, and 2005, respectively. She becomes an Assistant Professor, in 2011. She is currently as Assistant professor at the University of King Bin Abdul-Aziz for Health Science, Kingdom of Saudi Arabia. Her main areas of research interest are leadership, human resources, management styles, strategic planning, quality management and decision making with over 10 publications. She teaches "Basic principles and theories of management and leadership" at the undergraduate level, "Human Resources Management" "Health Care Delivery System" at the graduate level, and has taught "Management and Leadership Functions and Skills" abroad in Kingdom of Saudi Arabia. She has been the supervisor to the post graduate students run master and doctoral thesis for 6 years. In a previous life, she worked as a member of quality management department. 